\title{
LA COOPERACIÓN FINANCIERA CON CHINA: DE UN PASADO BRILLANTE CON EL FAD A LA BÚSQUEDA DE UN FUTURO CON EL FIEM
}

En el presente artículo, después de una amplia presentación de los orígenes y la evolución de la cooperación financiera con China, se esbozan las principales líneas del nuevo modelo de financiación de la cooperación empresarial con China que la Secretaría de Estado de Comercio quiere desarrollar con este país, al constatar la ausencia actual de proyectos empresariales en China financiados con apoyo oficial, tras el formidable desarrollo de la república popular y al dejar, en julio de 2012, de ser elegible en la OCDE para recibir créditos concesionales.

Palabras clave: financiación, cooperación empresarial, créditos, tipos de interés, amortización. Clasificación JEL: E43, E51.

\section{Introducción}

Desde que en los años ochenta del pasado siglo se inició la concesión de créditos del Fondo de Ayuda al Desarrollo (FAD) ${ }^{1}$ a China, este país se convirtió en el principal receptor de la cooperación financiera oficial española.

EI FAD fue un instrumento esencial para apoyar la entrada de empresas españolas en el mercado chino. De hecho, muchas empresas españolas presentes actualmente en China,

*Subdirector General de Fomento Financiero de la Internacionalización. Dirección General de Comercio Internacional e Inversiones.

**Jefe de Servicio. Subdirección General de Fomento Financiero de la Internacionalización. Dirección General de Comercio Internacional e Inversiones.

1 Fondo de Ayuda al Desarrollo (FAD): fondo sin personalidad jurídica, dotado por el Estado español para otorgar ayudas financieras de carácter concesional a países en vías de desarrollo o a sus empresas o instituciones públicas, así como a instituciones financieras gubernamentales. Creado por el Real Decreto-Ley 16/1976, de 24 de agosto. algunas de ellas de primerísimo orden en nuestra economía, entraron en el mercado chino gracias a proyectos financiados con el FAD.

Por otro lado, China ha honrado más que satisfactoriamente las obligaciones financieras contraídas con España con motivo de estos créditos, siendo los pagos recibidos de aquel país uno de los principales pilares de la actual sostenibilidad financiera del Fondo de Internacionalización de la Empresa fcpj $(\text { FIEM) })^{2}$.

\footnotetext{
2 Fondo para la Internacionalización de la Empresa fcpj (FIEM), creado por la Ley 11/2010, de 28 junio, de reforma del sistema de apoyo financiero a la internacionalización de la empresa española, como instrumento para promover las operaciones de exportación de las empresas españolas, así como las de inversión española directa en el exterior para fomentar la internacionalización de las empresas españolas.

Se nutre con las dotaciones establecidas anualmente en la Ley de Presupuestos Generales del Estado, los reembolsos de los créditos y préstamos concedidos y las comisiones e intereses generados. Desarrollado por el Real Decreto 1797/2010, de 30 de diciembre.
} 
No obstante, aquella época ha concluido. Frente a lo que normalmente se cree, el motivo no fue la transformación del FAD en el FIEM, ocurrida en el año 2010, al aprobarse la nueva normativa reguladora del FIEM. La causa real fue que el importante desarrollo de China y el consecuente crecimiento de su renta per cápita hicieron que dejara de ser, en julio de 2012, elegible en la OCDE para recibir créditos concesionales. De hecho, el último de ellos otorgado a China se concedió ya con el FIEM en pleno funcionamiento.

La abundancia de divisas y la facilidad de financiación, en general, en China hicieron que la financiación oficial española en términos comerciales no resultara tan atractiva para los clientes chinos. Ambos factores (ausencia de financiación concesional y abundancia de financiación comercial local) provocaron el agotamiento del modelo de cooperación financiera con China que tanto éxito había tenido en el pasado.

Tras unos años sin contar con proyectos empresariales en China financiados con apoyo oficial, estamos trabajando en la actualidad en desarrollar un nuevo modelo de financiación de la cooperación empresarial española con China. Este nuevo modelo se basaría en tres pilares:

1. La financiación de inversiones españolas productivas en China con garantías estrictamente privadas.

2. La financiación en términos comerciales, tanto con garantías públicas como privadas, de operaciones de exportación española, en particular proyectos de importes relativamente menores en los que se constatan mayores dificultades para su financiación bancaria.

3. La cooperación con China en la financiación conjunta de proyectos de interés mutuo en terceros mercados, donde volvería a tener cabida la financiación concesional si el país y el proyecto beneficiario fueran elegibles para este tipo de créditos.

La Administración española está haciendo un importante esfuerzo para desarrollar este nuevo modelo de cooperación financiera con China. Como siempre, su éxito radica en que las empresas españolas lo conozcan y lo aprovechen al máximo. Su divulgación es el objetivo último de este artículo. Así, en el mismo, haremos un repaso de los orígenes y evolución de la cooperación financiera, de su agotamiento y de las líneas del nuevo modelo a desarrollar.

\section{Orígenes de la cooperación financiera con China}

La cooperación financiera española con China comenzó hace casi 33 años con las primeras operaciones con cargo al Fondo de Ayuda al Desarrollo (FAD). El Consejo de Ministros de 18 de diciembre de 1985 aprobó los tres primeros créditos FAD a China, firmándose los respectivos convenios de crédito el 21 de marzo de1986. Esta relativa rapidez en la tramitación fue precisamente uno de los motivos principales del éxito de la cooperación financiera con China, ya que la Administración china demostró ser capaz de tramitar con una agilidad más que razonable un importante volumen de proyectos. Baste como ejemplo que tan solo pasaron tres meses entre la aprobación de la financiación por el Consejo de Ministros y la firma de los tres convenios de crédito, cuando normalmente este tipo de operaciones, y más si son las primeras, suelen llevar bastantes meses para formalizarse. 
Los tres primeros proyectos FAD con China consistían básicamente en:

- La exportación del equipo necesario para una planta de cítricos, financiados por un crédito FAD de 612 millones de pesetas, unos 3,6 millones de euros.

- Una planta de cementos en Benxi, con un crédito FAD de 250 millones de pesetas, unos 1,5 millones de euros.

- Una refinería de petróleo en Fujian, con un crédito FAD de 4.651 millones de pesetas, unos 27,9 millones de euros.

Estos tres créditos sumaban la cifra de 33,1 millones de euros, siendo este el total de la financiación concesional española concedida a China en aquel año 1985.

Las condiciones financieras de estos tres créditos, de acuerdo a las reglas establecidas en el denominado "Consenso OCDE" ${ }^{3}$, se establecieron a un tipo de interés del 2 por 100, con treinta años de amortización y diez de carencia.

\section{Consolidación del modelo de cooperación financiera: créditos mixtos, líneas de crédito y protocolos financieros}

Tras estos inicios de 1985, continuó un largo período de intensa aprobación de créditos FAD a China hasta que se agotó en 2009. El último de los FAD concedidos a China fue una línea de crédito para pequeños y medianos proyectos por importe de 40 millones de euros,

3 Consenso de la OCDE sobre Crédito a la Exportación con Apoyo Oficial, traspuesto a la normativa de la Unión Europea por el Reglamento UE N ․․ 1233/2011 del Parlamento Europeo y del Consejo, de 16 de noviembre de 2011, y demás normas de desarrollo. aprobada en el Consejo de Ministros del 18 de septiembre de aquel año.

El Cuadro 1 resume la aprobación de créditos FAD a China por años, alcanzándose entre 1985 y 2009 la importante cifra de 1.437 millones de euros concedidos a aquel país, con un total de 149 operaciones individuales aprobadas (y 18 líneas de crédito, que se tratarán en el siguiente apartado). El año 1991 fue el de mayor volumen de financiación aprobado, por importe de 135,6 millones de euros, siendo 2004 el año con el mayor número de $\triangleright$

CUADRO 1

CHINA. OPERACIONES FAD APROBADAS POR CONSEJO DE MINISTROS

\begin{tabular}{|c|c|c|c|}
\hline Año & $\begin{array}{l}\text { Importe FAD } \\
\text { en euros }\end{array}$ & $\begin{array}{c}\mathrm{N} .^{\circ} \mathrm{de} \\
\text { operaciones }\end{array}$ & $\begin{array}{c}\text { Líneas } \\
\text { de crédito }\end{array}$ \\
\hline 1985 & 33.133.797,32 & 3 & - \\
\hline 1986 & $7.508 .600,48$ & 1 & - \\
\hline 1987 & $14.018 .006,32$ & - & 1 \\
\hline 1988 & $36.060 .726,26$ & 1 & - \\
\hline 1989 & $68.092 .291,42$ & 6 & 1 \\
\hline 1990 & $55.365 .223,04$ & 5 & 1 \\
\hline 1991 & $135.576 .701,17$ & 9 & 3 \\
\hline 1992 & $109.173 .866,79$ & 3 & 一 \\
\hline 1993 & $62.977 .780,58$ & 6 & 1 \\
\hline 1994 & $59.777 .282,94$ & 2 & 2 \\
\hline 1995 & $115.685 .947,13$ & 4 & 2 \\
\hline 1996 & $1.854 .657,00$ & 1 & 一 \\
\hline 1997 & $64.772 .366,67$ & 6 & - \\
\hline 1998 & $32.116 .806,70$ & 6 & 1 \\
\hline 1999 & $77.259 .577,44$ & 10 & 1 \\
\hline 2000 & $25.508 .203,82$ & 9 & - \\
\hline 2001 & $99.134 .003,34$ & 9 & - \\
\hline 2002 & $27.005 .805,00$ & 7 & - \\
\hline 2003 & $92.746 .578,00$ & 20 & 1 \\
\hline 2004 & $44.243 .819,00$ & 24 & - \\
\hline 2005 & $99.668 .335,00$ & 8 & 1 \\
\hline 2006 & $43.925 .068,00$ & 6 & - \\
\hline 2007 & $13.825 .000,00$ & 2 & - \\
\hline 2008 & $40.000 .000,00$ & - & 2 \\
\hline 2009 & $77.734 .732,00$ & 1 & 1 \\
\hline Total & $1.437 .165 .175,42$ & 149 & 18 \\
\hline
\end{tabular}


operaciones empresariales aprobadas, nada menos que 24 de ellas.

En el anexo a este artículo se ofrece un breve resumen de los créditos FAD concedidos a China por Consejo de Ministros en cada uno de los años en que funcionó este sistema.

El desglose por sectores del total de créditos FAD concedidos a China muestra que el sector de bienes de equipos absorbió cerca de un tercio de la financiación aprobada (32 por $100)$, seguido a cierta distancia por los sectores de transporte (14 por 100), eléctrico (11 por 100) y de telecomunicaciones (8 por 100). El Cuadro 2 y el Gráfico 1 resumen los principales sectores financiados entre 1985 y 2009.

Este éxito del FAD en China estuvo basado en la necesidad china de acelerar su desarrollo económico, importando equipos y componentes extranjeros de alta tecnología para sus necesidades de inversión. Para financiar estas importaciones, China aprovechaba al máximo las facilidades financieras que ofrecían los Gobiernos de los países suministradores, en este caso el español mediante el FAD. Conforme China fue avanzando económicamente, estas necesidades se redujeron, de ahí que el modelo se fuera agotando, hasta acabar la concesión de créditos FAD en 2009, a pesar de que China siguió siendo elegible para recibir financiación concesional hasta 2012.

La cooperación financiera con China fue, asimismo, un éxito por la ya mencionada capacidad de gestionar proyectos de la Administración china, que, junto a la inexistencia de problemas de recobro de los créditos, animaba a la Administración española a maximizar la concesión de créditos FAD a China.

Por el lado español, además del buen desempeño de nuestras empresas, se supo aprovechar al máximo los diversos mecanismos y modalidades de la cooperación financiera de
CUADRO 2

CRÉDITOS FAD POR SECTORES

\begin{tabular}{|l|c|c|}
\hline \multicolumn{1}{|c|}{ Sectores } & $\begin{array}{c}\text { Importe } \\
\text { en euros }\end{array}$ & Porcentaje \\
\hline Bienes de equipo & $458.640 .079,28$ & 32 \\
Transporte & $194.386 .253,51$ & 14 \\
Eléctrico & $151.545 .862,28$ & 11 \\
Telecomunicación & $108.117 .362,05$ & 8 \\
Infraestructura & $60.873 .108,00$ & 4 \\
Medio ambiente & $60.153 .805,76$ & 4 \\
Sanidad & $44.902 .963,41$ & 3 \\
Educación & $15.695 .430,00$ & 1 \\
Otros & 342.850.311,13 & 24 \\
Total & 1.437.165.175,42 & $\mathbf{1 0 0}$ \\
\hline Fuente: elaboración propia a partir de datos de la S.G. de Fomento \\
\hline \multicolumn{2}{|l|}{ Financiero de la Internacionalización. }
\end{tabular}

GRÁFICO 1

DISTRIBUCIÓN SECTORIAL DE LOS CRÉDITOS FAD A CHINA

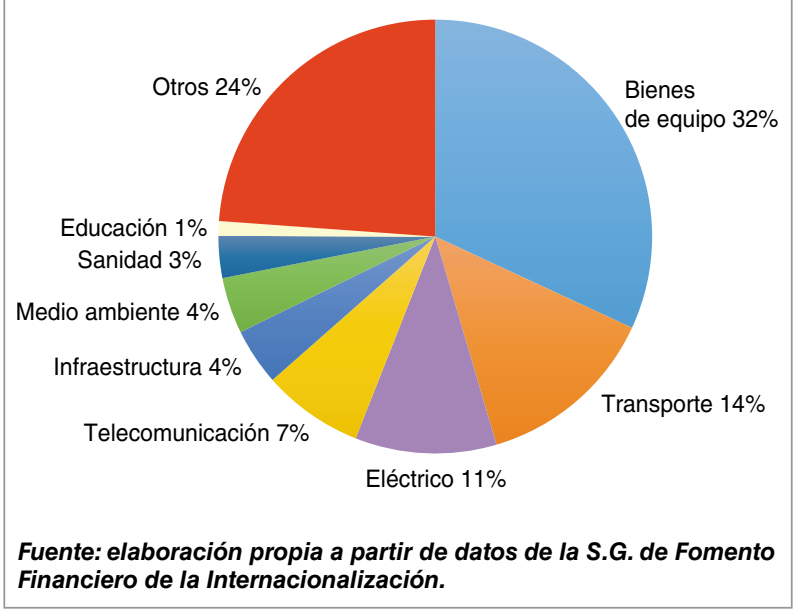

entonces, recurriendo con profusión a fórmulas como los "créditos mixtos", las líneas de crédito para pequeños proyectos y los protocolos de cooperación financiera. Analizaremos brevemente cada uno de ellos.

\subsection{Los créditos mixtos}

El crédito mixto consistía en financiar un determinado proyecto de exportación española a China mediante la combinación de un crédito FAD y un crédito bancario, asegurado por $D$ 
CESCE por cuenta del Estado, que normalmente también se beneficiaba de un apoyo a los tipos de interés bajo el sistema $\mathrm{CARI}^{4}$. Este sistema de financiación de proyectos, normalmente al 50 por 100 por cada instrumento financiero, permitía duplicar el impacto de los créditos FAD a la vez que ayudaba a introducir a la banca española en el mercado financiero chino. Los créditos mixtos demostraron, de nuevo, ser todo un acierto, elevando la cooperación financiera con China a sus mayores cotas.

El sistema, aunque resultó un éxito clamoroso, no obstante, también tenía sus inconvenientes. Desde nuestro punto de vista, el principal de ellos era que para poder obtener un grado de concesionalidad ${ }^{5}$ mínimo del 35 por 100 del conjunto del paquete financiero, como marcaba el Consenso OCDE tras la aprobación a principios de los años noventa del denominado «Paquete de Helsinki», y teniendo en cuenta que la concesionalidad del tramo comercial era cero por definición, el tramo FAD debía tener una concesionalidad del 70 por 100 , lo que hacía que sus condiciones financieras fueran extraordinariamente blandas. Además, en las ocasiones en que se producía un abaratamiento de los tipos de interés en el mercado frente a los tipos fijos del crédito comercial

4 El CARI, Convenio de Ajuste Recíproco de Intereses, es un sistema de estabilización de intereses, instrumentado por el Instituto de Crédito Oficial (ICO) por encomienda de la Secretaría de Estado de Comercio. Permite a los bancos financiar a largo plazo los tipos fijos marcados por la OCDE (CIRR, Commercial Interest Rate of Reference), asegurándose por otra parte que perciben una remuneración mínima del euribor (para euros) o libor (para dólares), más un margen de gestión reconocido por la Administración. Garantiza, así, que sean compatibles los intereses del cliente (recibir financiación a largo plazo a tipos fijos) con los del financiador (percibir una remuneración acorde con las condiciones del mercado en un determinado momento, más un determinado margen garantizado).

5 La concesionalidad de un crédito se define como el elemento de donación implícito en un crédito cuando se compara el valor actualizado neto del flujo de recobros del crédito, basado en sus condiciones financieras, con las de mercado, que por definición son el nominal del crédito. El flujo de recobros se lleva a valor presente utilizando la tabla de tasas de descuentos por plazos y monedas (llamados DDR, Diferenciated Discount Rates) que publica anualmente la OCDE. original, el cliente chino prefería amortizar anticipadamente el tramo comercial de la financiación, permaneciendo en vigor únicamente el tramo FAD, con un 70 por 100 de concesionalidad, lo que resultaba a todas luces excesivo. Para combatir este problema, se elevó la comisión de cancelación anticipada de los CARI para intentar que esa práctica no perjudicara los calendarios de amortización de este otro instrumento financiero oficial.

En realidad, y aunque no sea el objeto principal de este artículo, el uso de la fórmula de los créditos mixtos y las ventajas propias del CARI hicieron que este instrumento financiero fuera tan utilizado en China como el FAD, incluso algo más, como muestra el Cuadro 3 , donde se desglosan por años las operaciones CARI formalizadas con China, con una cifra final de créditos CARI formalizados de nada menos que 1.976,6 millones de euros al cambio actual.

\subsection{Las líneas de crédito para pequeños proyectos}

En 1987, dos años después de que se iniciaran las relaciones de cooperación financiera con la República Popular China, se aprobó otro instrumento importantísimo para el éxito de esta cooperación: las líneas de crédito con cargo al FAD.

La finalidad de estas líneas era poner a disposición de aquel país facilidades de financiación de pequeños proyectos, destinados al fortalecimiento del tejido económico y empresarial chino, con un procedimiento de tramitación más sencillo y ágil que los créditos FAD ordinarios.

El objetivo de la Administración española era favorecer la entrada en el mercado $D$ 
CUADRO 3

OPERACIONES CARI FORMALIZADAS CON CHINA

\begin{tabular}{|c|c|c|c|c|}
\hline \multirow{2}{*}{ Año } & \multicolumn{2}{|c|}{ Operaciones en euros } & \multicolumn{2}{|c|}{ Operaciones en USD } \\
\hline & N. ${ }^{\circ}$ de operaciones & Importe & $\mathrm{N} .^{\circ}$ de operaciones & Importe \\
\hline 1988 & 1 & $30.700 .450,00$ & 1 & $28.106 .086,07$ \\
\hline 1989 & - & - & 1 & $27.569 .880,49$ \\
\hline 1990 & 1 & $2.064 .508,30$ & 11 & $31.011 .041,50$ \\
\hline 1991 & 2 & $269.055,16$ & 9 & $35.575 .064,30$ \\
\hline 1992 & 6 & $5.379 .153,00$ & 12 & $178.409 .987,85$ \\
\hline 1993 & 2 & $3.685 .198,92$ & 6 & $196.991 .639,30$ \\
\hline 1994 & 3 & $64.598 .985,31$ & 21 & $609.607 .469,60$ \\
\hline 1995 & - & - & 36 & $156.651 .963,50$ \\
\hline 1996 & - & - & 15 & $111.483 .123,47$ \\
\hline 1997 & - & - & 15 & $246.988 .026,50$ \\
\hline 1998 & - & - & 22 & $157.626 .172,12$ \\
\hline 1999 & - & - & 19 & $33.530 .838,00$ \\
\hline 2000 & 1 & $2.023 .838,56$ & 11 & $30.451 .561,00$ \\
\hline 2001 & - & - & 15 & $28.646 .497,02$ \\
\hline 2002 & - & - & 11 & $49.492 .449,30$ \\
\hline 2003 & 6 & $24.386 .006,70$ & 12 & $15.711 .274,50$ \\
\hline 2004 & 6 & $9.578 .224,06$ & 13 & $19.404 .614,50$ \\
\hline 2005 & 23 & $33.692 .102,07$ & 1 & $1.400 .000,00$ \\
\hline 2006 & 19 & $90.345 .481,84$ & - & - \\
\hline 2007 & 19 & $25.142 .177,50$ & - & - \\
\hline 2008 & 17 & $29.301 .663,52$ & - & - \\
\hline 2009 & 13 & $52.939 .731,17$ & - & - \\
\hline 2010 & 4 & $6.555 .051,29$ & - & - \\
\hline 2011 & 3 & $4.604 .965,35$ & - & - \\
\hline 2012 & 1 & $16.830 .000,00$ & - & - \\
\hline Total general & 127 & $402.096 .592,75$ & 231 & $1.958 .657 .689,02$ \\
\hline
\end{tabular}

chino de la pequeña y mediana empresa española, apoyando financieramente sus operaciones de suministro y equipamiento llave en mano, así como fortalecer los lazos económicos y empresariales entre las empresas españolas y el dinámico e incipiente tejido económico y empresarial que se estaba desarrollando en China.

Estas líneas, al igual que líneas equivalentes establecidas por España con otros países, permiten una tramitación mucho más ágil de las operaciones de menor importe, al no requerir que cada operación individual tenga que cumplir con la totalidad de los trámites habituales. También son de enorme utilidad para anunciar a las empresas españolas y sus clientes chinos la existencia de un marco de financiación disponible para posibles proyectos y animarlos así a emprenderlos conjuntamente.

La primera línea de crédito para pequeños proyectos en China, por importe de 20 millones de dólares, unos 14 millones de euros al cambio, fue aprobada por Consejo de Ministros $\triangle$ 
CUADRO 4

LÍNEAS DE CRÉDITO FAD A CHINA

\begin{tabular}{|c|c|c|c|c|c|c|}
\hline $\begin{array}{l}\text { Aprobación S.E. } \\
\text { de Comercio }\end{array}$ & $\begin{array}{c}\text { Consejo } \\
\text { de Ministros }\end{array}$ & $\begin{array}{l}\text { Convenio } \\
\text { crédito }\end{array}$ & $\begin{array}{c}\text { Importe } \\
\text { en dólares }\end{array}$ & $\begin{array}{l}\text { Importe } \\
\text { en euros }\end{array}$ & Operaciones & $\begin{array}{c}\text { Saldo imputado } \\
\text { en euros }\end{array}$ \\
\hline 1987 & 23/09/1988 & 13/01/1989 & $20.000 .000,00$ & $14.018 .006,32$ & 12 & 13,84 \\
\hline 1989 & 05/01/1990 & $13 / 05 / 1990$ & $15.000 .000,00$ & $9.867 .116,22$ & 10 & 9,55 \\
\hline 1990 & 02/11/1990 & 25/02/1991 & $30.000 .000,00$ & $18.394 .576,47$ & 16 & 17,93 \\
\hline 1991 & 05/07/1991 & 10/09/1991 & $15.000 .000,00$ & $10.396 .307,38$ & 6 & 9,78 \\
\hline 1991 & 05/07/1991 & 10/09/1991 & $15.000 .000,00$ & $10.396 .307,38$ & 6 & 10,35 \\
\hline 1992 & 21/02/1992 & 23/06/1992 & $15.000 .000,00$ & $9.206 .303,42$ & 7 & 8,68 \\
\hline 1993 & 19/11/1993 & 25/01/1994 & $8.880 .000,00$ & 7.336.106,52 & 10 & 5,38 \\
\hline 1994 & 08/07/1994 & 10/05/1995 & $20.000 .000,00$ & $15.696 .032,12$ & 24 & 15,12 \\
\hline 1994 & 29/12/1994 & 01/07/1996 & $20.000 .000,00$ & $15.899 .174,21$ & 19 & 15,68 \\
\hline 1995 & 22/12/1995 & 20/05/1997 & $20.000 .000,00$ & $14.712 .776,32$ & 15 & 12,60 \\
\hline 1995 & 28/12/1995 & 11/08/1998 & $20.000 .000,00$ & 14.603.392,11 & 5 & 4,54 \\
\hline 1999 & $30 / 10 / 1998$ & 06/04/1999 & $20.000 .000,00$ & $16.895 .652,28$ & 17 & 16,15 \\
\hline 1999 & 23/12/1999 & 17/08/2000 & $20.000 .000,00$ & 19.719.207,15 & 5 & 4,99 \\
\hline 2003 & $12 / 12 / 2003$ & 03/11/2004 & - & $25.812 .237,00$ & 27 & 25,89 \\
\hline 2005 & 02/09/2005 & 16/01/2006 & - & $50.000 .000,00$ & 38 & 49,79 \\
\hline 2008 & 07/03/2008 & - & - & $20.000 .000,00$ & 14 & 19,60 \\
\hline 2009 & 18/09/2009 & - & - & $40.000 .000,00$ & 5 & 8,15 \\
\hline Totales & - & - & - & $312.953 .194,90$ & 236 & 248,02 \\
\hline
\end{tabular}

de 4 diciembre de 1987, a un tipo de interés de un 3 por 100, con un periodo de amortización de diez años, en el que se incluía una carencia de siete años.

Tras esta primera línea de crédito se llegaron a aprobar dieciséis líneas más, siendo aprobada la última de ellas en Consejo de Ministros en septiembre de 2009 , el ya mencionado último crédito FAD concedido a China.

Para hacer estas líneas lo más competitivas posible, los tipos de interés fueron bajando a lo largo del periodo de utilización de este instrumento, hasta llegar a un mínimo del 0,15 por 100 anual. Asimismo, los periodos de amortización fueron aumentando desde los 15-20 años de las primeras líneas hasta alcanzar los 30-36 años de las últimas.

El total de fondos puestos a disposición mediante líneas de crédito durante esos años alcanzó los 312,9 millones de euros. Se imputaron a las líneas 236 operaciones de empresas españolas, por un importe FAD de 248 millones de euros. El importe medio de financiación FAD fue, por tanto, de 1,05 millones de euros por operación, lo que muestra claramente el relativamente reducido tamaño de estas operaciones. El Cuadro 4 ofrece un desglose de las líneas de crédito FAD aprobadas para China.

La aprobación y utilización de líneas de crédito con China fue tan intensa que en cuatro años (concretamente en los años 1990, 1991, 1994 y 1995) se llegaron a aprobar dos líneas de crédito FAD a China por año. Incluso se llegaron a aprobar dos líneas en un mismo Consejo de Ministros, como fue el caso del Consejo reunido el 5 de julio de 1991, teniendo cada una un importe de 15 millones de dólares, el equivalente a 10,4 millones de euros al cambio. 


\subsection{Los protocolos de cooperación financiera}

En el marco de unas relaciones bilaterales cada vez más fluidas con la República Popular China, y con la finalidad de estrechar las relaciones de cooperación técnica y económica entre ambas partes, se firmaron diversos Programas de Cooperación Financiera con el Ministerio de Finanzas (MOF) de ese país.

Estos programas no suponían una obligación financiera para España, y se firmaban

CUADRO 5

FONDO DE AYUDA AL DESARROLLO (FAD)

DIEZ PRIMEROS PAÍSES RECEPTORES

APROBACIONES CONSEJO DE MINISTROS 1976-2010

\begin{tabular}{|l|c|}
\hline \multicolumn{1}{|c|}{ País } & Importe en euros \\
\hline China & $1.437 .165 .175,42$ \\
Marruecos & $792.360 .622,94$ \\
Argelia & $538.808 .572,70$ \\
México & $521.651 .370,91$ \\
Turquia & $501.522 .548,10$ \\
Túnez & $482.061 .034,57$ \\
Argentina & $476.608 .812,33$ \\
Indonesia & $414.861 .355,72$ \\
Angola & $395.192 .896,00$ \\
Ecuador & $333.558 .829,73$ \\
Total & $\mathbf{5 . 8 9 3 . 7 9 1 . 2 1 8 , 4 1}$ \\
\hline Fuente: elaboración propia a partir de datos de la S.G. de Fomento \\
Financiero de la Internacionalización. \\
\hline
\end{tabular}

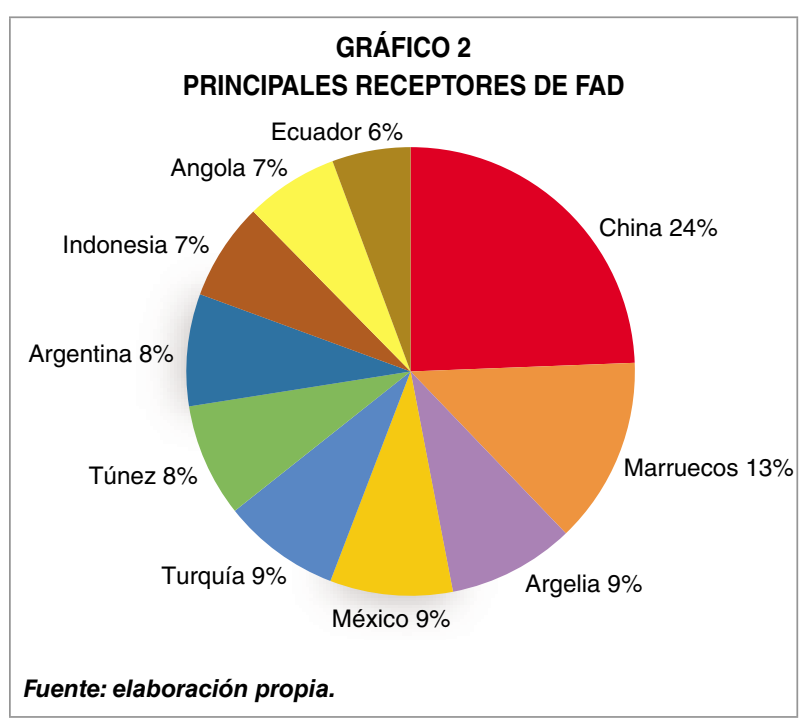

bajo la modalidad de Acuerdos de Intenciones (MOU, Memorandum of Understanding en inglés). Mostraban la voluntad de España de poner a disposición de China facilidades financieras con apoyo oficial para el suministro de bienes y servicios españoles en proyectos de interés acordados por ambas partes y llevados a cabo por empresas españolas.

Los programas se renovaban cada dos años, siendo el último de ellos firmado en octubre de 2008. Ese programa tenía un importe total de 380 millones, y el grueso de la oferta de financiación española se centró en proyectos tecnológico-industriales, de mayor valor añadido e imagen para España. A pesar de esta innovación, su utilización fue muy escasa, al ser firmado en una época en la que el modelo de cooperación financiera ya se estaba agotando claramente, lo que llevó a que no se renovara posteriormente.

El uso combinado de los tres instrumentos mencionados (créditos mixtos, líneas de crédito y protocolos financieros) y la gran capacidad de procesamiento de proyectos y de repago de créditos de China hizo que este país se convirtiera en el primer receptor de créditos FAD, a una importante distancia del resto de países receptores, como muestran el Gráfico 2 y el Cuadro 5. China percibió un 24 por 100 de los créditos FAD concedidos, situándose a una importante distancia de los siguientes países receptores: Marruecos (13 por 100), Argelia (9 por 100) y Turquía, México y Túnez (8 por 100 cada uno).

\section{Agotamiento del modelo: la transformación del FAD en FIEM y la graduación de China en la OCDE}

La doble finalidad del FAD, de financiar, por un lado, las exportaciones españolas a $D$ 
determinados mercados de interés y, por otro, de apoyar el desarrollo de los países beneficiarios de estos créditos, aunque era compatible en teoría, fue cada vez más difícil de instrumentar en la práctica. Se generaron importantes tensiones que hicieron cada vez más compleja la gestión del instrumento.

Lo anterior, junto con la voluntad del Gobierno de aquella época de que España contara con una cooperación al desarrollo más «limpia» de instrumentos e intereses comerciales, llevó a que se tomara la decisión de dividir el FAD en dos instrumentos financieros oficiales con objetivos netamente diferenciados: el Fondo para la Promoción del Desarrollo (FONPRODE), fondo que, como indica su nombre, tenía el objetivo de financiar proyectos de desarrollo cuyas actividades serían desligadas y debían ser computadas dentro de la Ayuda Oficial al Desarrollo (AOD) española, y el Fondo para la Internacionalización de la Empresa (FIEM), que, como también indica su nombre, apoyaba la internacionalización de las empresas españolas, no pudiendo computarse sus recursos dentro de la AOD española.

Así, la Ley 11/2010, de 28 de junio, de Reforma del Sistema de Apoyo Financiero a la Internacionalización, creó el Fondo para la Internacionalización de la Empresa (FIEM). Tal y como establecía esta ley, se procedió al cierre contable del FAD y se efectuó la transferencia de activos y pasivos del FAD para la internacionalización al nuevo FIEM (y, paralelamente, los activos correspondientes al FONPRODE pasaron a dicho fondo). El reglamento del FIEM se aprobó mediante el Real Decreto 1797/2010, de 30 de diciembre, y entró en vigor el 20 de enero de 2011.

El último crédito concesional concedido a China fue precisamente con cargo al FIEM, como se ha señalado al principio de este artículo. Este crédito fue aprobado en el Consejo de Ministros del 2 de diciembre de 2011, ya con el FIEM plenamente en vigor. Se destinó a la financiación de dos simuladores de vuelo y servicios auxiliares dentro de una operación de exportación de cuatro simuladores para Hainan Airlines, por un valor conjunto de unos 45 millones de euros.

El crédito FIEM tenía un importe de 25,2 millones de euros, con una tasa de concesionalidad del 80,26 por 100, calculada de acuerdo a las normas del Consenso de la OCDE. El plazo de amortización de dicho crédito era de 47 años, con treinta años de gracia y un tipo de interés del 0,1 por 100 anual.

Por tanto, el último de los créditos aprobados para China lo fue bajo el FIEM, y en condiciones altamente concesionales, no teniendo impacto alguno la transformación de FAD en FIEM en la cooperación financiera con China.

Sí lo tuvo, y mucho, el acelerado desarrollo económico de China, proceso que la ha llevado a ser actualmente la segunda economía del mundo tras EEUU. En 1978 China inició un proceso de apertura y transformación económica, cuya principal consecuencia fue que la tasa de crecimiento media de su PIB se situó en tasas cercanas al 10 por 100 anual. Su economía, así como sus patrones de consumo, también experimentaron importantes transformaciones. Su incorporación en diciembre de 2001 a la Organización Mundial de Comercio aceleró este rápido proceso de cambios.

Como consecuencia de este proceso de intenso desarrollo se produjo un incremento de la renta per cápita en aquel país, que hizo que China dejara de ser elegible en la OCDE para recibir financiación concesional. Esto ocurrió en julio de 2012, al pasar a formar parte de los países no elegibles por la OCDE para poder percibir este tipo de cooperación financiera. Por $\square$ 
CUADRO 6

CHINA. OPERACIONES FORMALIZADAS Y RECOBROS POR AÑO

\begin{tabular}{|c|c|c|c|c|c|c|c|}
\hline \multirow{2}{*}{ Año } & \multicolumn{2}{|c|}{ Operaciones en euros } & \multicolumn{2}{|c|}{ Operaciones en USD } & \multirow{2}{*}{ Año } & \multirow{2}{*}{$\begin{array}{l}\text { Recobros } \\
\text { en euros }\end{array}$} & \multirow{2}{*}{$\begin{array}{c}\text { Recobros } \\
\text { en USD }\end{array}$} \\
\hline & N. operac. & Importe & N. ${ }^{\circ}$ operac. & Importe & & & \\
\hline 1986 & 1 & $2.666 .937,20$ & - & - & - & - & - \\
\hline 1988 & 1 & $36.060 .726,26$ & - & - & - & - & - \\
\hline 1989 & 1 & $1.707 .881,63$ & 6 & $69.219 .668,75$ & - & - & - \\
\hline 1990 & 1 & $9.866 .845,77$ & 3 & $31.265 .394,00$ & - & - & - \\
\hline 1991 & 1 & $10.449 .681,62$ & 10 & $157.124 .544,00$ & - & - & - \\
\hline 1992 & - & - & 8 & $292.915 .434,00$ & 1992 & $153.258,09$ & $618.829,10$ \\
\hline 1993 & 2 & $3.137 .857,06$ & 2 & $26.666 .619,50$ & 1993 & - & $1.237 .584,00$ \\
\hline 1994 & - & - & 4 & $63.870 .000,00$ & 1994 & - & $1.237 .584,00$ \\
\hline 1995 & - & - & 10 & $44.150 .818,00$ & 1995 & - & $1.237 .584,00$ \\
\hline 1996 & - & - & 4 & $51.567 .500,00$ & 1996 & - & $1.237 .584,00$ \\
\hline 1997 & - & - & 4 & $94.516 .716,50$ & 1997 & $132.908,20$ & $1.237 .584,00$ \\
\hline 1998 & - & - & 13 & $49.111 .910,40$ & 1998 & $132.908,20$ & $1.237 .584,00$ \\
\hline 1999 & - & - & 12 & $44.628 .796,50$ & 1999 & $7.281 .900,42$ & $3.725 .621,34$ \\
\hline 2000 & 1 & $2.042 .447,06$ & 6 & $45.283 .443,37$ & 2000 & $8.326 .621,10$ & $8.170 .428,12$ \\
\hline 2001 & - & - & 11 & $45.992 .148,50$ & 2001 & $9.285 .947,70$ & $16.889 .721,62$ \\
\hline 2002 & - & - & 8 & $56.838 .447,50$ & 2002 & $11.368 .198,12$ & $28.935 .757,08$ \\
\hline 2003 & 4 & $18.059 .925,22$ & 8 & $45.010 .979,50$ & 2003 & $11.504 .626,75$ & $40.627 .728,57$ \\
\hline 2004 & 42 & $61.859 .052,27$ & 6 & $7.755 .860,50$ & 2004 & $4.492 .063,04$ & $40.367 .605,64$ \\
\hline 2005 & 14 & $24.973 .827,69$ & 6 & $8.294 .554,50$ & 2005 & $4.768 .001,70$ & $39.536 .325,51$ \\
\hline 2006 & 40 & $132.423 .319,55$ & - & - & 2006 & $1.338 .144,66$ & $35.409 .459,10$ \\
\hline 2007 & 4 & $18.585 .741,84$ & - & - & 2007 & $491.159,42$ & $34.882 .110,78$ \\
\hline 2008 & 16 & $20.000 .000,00$ & - & - & 2008 & 491.159,42 & $35.354 .794,48$ \\
\hline 2009 & 8 & $78.452 .525,03$ & - & - & 2009 & $5.310 .159,42$ & $37.215 .329,76$ \\
\hline 2012 & 1 & $25.200 .000,00$ & - & - & 2010 & $542.220,61$ & $37.306 .031,99$ \\
\hline- & - & - & - & - & 2011 & $593.281,78$ & $39.655 .492,80$ \\
\hline- & - & - & - & - & 2012 & $593.281,78$ & $37.834 .915,26$ \\
\hline- & - & - & - & - & 2013 & $2.294 .702,54$ & $38.785 .898,09$ \\
\hline- & - & - & - & - & 2014 & $3.555 .182,60$ & $50.733 .767,82$ \\
\hline- & - & - & - & - & 2015 & $3.328 .770,39$ & $42.719 .136,74$ \\
\hline- & - & - & - & - & 2016 & $4.838 .332,29$ & $41.404 .419,37$ \\
\hline - & - & - & - & - & 2017 & $6.239 .510,14$ & $47.703 .634,10$ \\
\hline Total & 137 & $445.486 .768,20$ & 121 & $1.134 .212 .835,52$ & Recobros & $87.062 .338,37$ & $665.302 .511,27$ \\
\hline Formalizaciones & - & $445.486 .768,20$ & - & $1.134 .212 .835,52$ & - & - & - \\
\hline Recobros & - & $87.062 .338,37$ & - & $665.302 .511,27$ & - & - & - \\
\hline
\end{tabular}

tanto, a partir de esa fecha, y con la excepción de aquellos créditos que hubieran sido notificados con anterioridad, China solo podía percibir créditos oficiales españoles en las condiciones comerciales que establece el Consenso OCDE.

La abundancia de financiación comercial en el mercado chino y la imposibilidad señalada de conceder financiación concesional fueron los factores que realmente condujeron al agotamiento definitivo del modelo de cooperación financiera con China, modelo que, como hemos indicado ya, venía mostrando signos de agotamiento desde años anteriores. 


\section{Contribución de China a la sostenibilidad del FAD-FIEM}

Aunque la concesión de nuevos créditos FAD-FIEM a China concluyera en el año 2011, al tratarse de operaciones con un importante grado de concesionalidad, los créditos tenían unos calendarios de repago bastante amplios, por lo que China ha estado amortizando durante todos estos años los créditos concedidos. De hecho, los seguirá amortizando durante un buen tiempo.

Lo anterior conlleva un cierto beneficio diferido de la amplia cooperación financiera mantenida con China. La financiación del fondo FIEM se compone de los ingresos de créditos anteriores y de nuevas dotaciones presupuestarias. En una época de austeridad presupuestaria como la que hemos vivido, y seguimos viviendo, cuanto mayores sean los ingresos percibidos de créditos anteriores, menores serán las necesidades de recurrir a los Presupuestos Generales del Estado. Este ha sido el caso para el FIEM desde el año 2011, ya que desde ese año no ha habido necesidad de utilizar las dotaciones presupuestarias habilitadas al efecto.

En este logro ha tenido mucho que ver la devolución en tiempo y forma de los créditos concedidos a China, como muestra el importante flujo de recobros obtenido reflejado en la segunda parte del Cuadro 6.

Como también muestra este cuadro, la importante diferencia todavía existente entre operaciones formalizadas y recobros obtenidos augura que este flujo de recobros se va a mantener durante un buen tiempo, contribuyendo notablemente a la autofinanciación presente y futura del FIEM y permitiendo al fondo conceder nuevos créditos a otros proyectos y países, generando así un cierto efecto redistributivo de esta financiación.

\section{Búsqueda de un nuevo modelo de cooperación con el FIEM}

El agotamiento del modelo anterior y el hecho de que durante cerca de ocho años no se hayan concedido nuevos créditos FIEM a China nos debe animar a buscar nuevas vías y posibilidades para reactivar la cooperación financiera con China. EI FIEM es un instrumento muy potente de política comercial, y creemos que España no puede ni debe renunciar a su utilización con China, más aún en el contexto del diseño y lanzamiento de nuevas iniciativas de promoción de la presencia empresarial española en China (como el programa actualmente en preparación denominado PASE China).

El hecho de que el FIEM no sea simplemente la mera renovación del FAD, una vez eliminado su componente de ayuda al desarrollo, sino que amplíe su campo de actuación a nuevas modalidades de crédito como el crédito comercial de exportación, o que admita la utilización de garantías diferentes de la soberana, incluyendo garantías de proyecto, project finance, y que se amplíe a la financiación de inversiones, hace que se abran nuevas posibilidades de utilización del FIEM en China.

Igualmente, por parte china surgen nuevas oportunidades por el relativo agotamiento de la época de financiación local abundante en el país asiático. En este entorno se incrementan las posibilidades de recurrir a la financiación comercial extranjera, que, además, especialmente para el caso de créditos denominados en euros, tiene un coste altamente competitivo, al menos mientras no suban significativamente los tipos oficiales.

Por otra parte, aunque todavía con bastante timidez e incluso recelos por ambas partes, aparecen cada vez más operaciones empresariales, sino españolas, en terceros mercados, $D$ 
donde sería factible ofrecer soluciones financieras combinadas. Se puede recurrir de nuevo, incluso, a la financiación concesional, si el país de destino y el proyecto en cuestión fueran elegibles para este tipo de financiación de acuerdo al Consenso OCDE.

Aunque hasta la fecha no se han obtenido resultados tangibles, sí es cierto que las Administraciones china y española están realizando un importante esfuerzo para desarrollar y concretar estas vías de trabajo, como muestran los abundantes contactos mantenidos en los últimos meses sobre estos temas con diversas contrapartes gubernamentales y financieras chinas.

Hay dos iniciativas concretas, desarrolladas por ICEX con apoyo de las Oficinas Económicas y Comerciales de España en China y del FIEM, que han generado excelentes oportunidades en este ámbito. Así, del 6 al 8 de julio del 2016, se celebró en Pekín un Partenariado Multilateral bajo el título de «Oportunidades conjuntas en la Franja y la Ruta, y en los mercados globales", cuyo objetivo fue la difusión del FIEM y los terceros mercados. La segunda actividad fue el seminario realizado en diciembre de 2017 en Pekín, organizado por la National Development and Reform Commission de China (NDRC) y la Secretaría de Estado de Comercio, sobre oportunidades empresariales conjuntas en terceros mercados y su posible financiación conjunta, al que asistieron numerosas empresas, entidades financieras y organismos oficiales de ambos países.

Igualmente, para la financiación comercial de exportaciones ya hay algunas operaciones en las que estamos trabajando y a las que hemos concedido cartas de intención de financiación FIEM. EI PASE China contempla una vía de trabajo específica a desarrollar en este campo, como es la celebración de reuniones con las oficinas locales del Ministerio de Finanzas (MOF), incluyendo presentaciones a empresas, sobre las posibilidades de financiación de pequeños proyectos con cargo al FIEM, posibilidades ampliamente mejoradas tras la aprobación en julio de 2017 de una línea de crédito FIEM para financiar de una forma más sencilla y ágil proyectos de menos de tres millones de euros.

Por último, la financiación con crédito FIEM de inversiones productivas españolas en China siempre está abierta a cualquier empresa española que quiera solicitarlo, además de otras posibilidades de financiación vía COFIDES y/o CESCE.

Confiamos en que las circunstancias actuales del mercado financiero chino, las nuevas modalidades de financiación existentes con el FIEM y el trabajo que se está desarrollando entre ambas Administraciones fructifiquen pronto en proyectos empresariales concretos, y que la cooperación financiera con China vuelva a tener una nueva época de esplendor. Pero todo ello, pasa necesariamente por que las empresas españolas y sus socios y clientes chinos conozcan estas facilidades financieras con cargo al FIEM y las utilicen a su pleno potencial.

\section{Bibliografía}

[1] ESPAÑA. Ley $11 / 2010$, de 28 de junio, de reforma del sistema de apoyo financiero a la internacionalización de la empresa española.

[2] ESPAÑA. Ley $38 / 2006$, de 7 de diciembre, Reguladora de la Gestión de la Deuda Externa.

[3] ESPAÑA. Real Decreto 1797/2010, de 30 de diciembre, por el que se aprueba el reglamento del fondo para la internacionalización de la empresa. 
[4] INSTITUTO DE CRÉDITO OFICIAL (2018). Bases de datos FIEM.

[5] OECD (2011). Arrangement on Officially Supported Export Credits. OECD. Consenso de la OCDE sobre Crédito a la Exportación con Apoyo Oficial, traspuesto a la normativa de la Unión Europea por el Reglamento UE N.. 1233/2011 del Parlamento Europeo y del Consejo, de 16 de noviembre de 2011, y demás normas de desarrollo.

\section{ANEXO \\ RESUMEN DE LOS CRÉDITOS FAD APROBADOS A CHINA POR AÑO DE APROBACIÓN}

\section{5}

Se aprobaron tres proyectos. La exportación del equipo necesario para una planta de cítricos, financiados por un crédito FAD de 612 millones de pesetas, unos 3,6 millones de euros. Una planta de cementos en Benxi, con un crédito FAD de 250 millones de pesetas, unos 1,5 millones de euros. Una refinería de petróleo en Fujian, con un crédito FAD por importe de 4.651 millones de pesetas, unos 27,9 millones de euros.

\section{6}

Se aprobó un proyecto de una planta de sulfato diamónico, con un crédito FAD por importe de 10,11 millones de dólares, unos 7,5 millones euros. El crédito se concedió en las mismas condiciones financieras de los créditos anteriores.

\section{7}

La primera línea de crédito para pequeños proyectos en China, por importe de 20 millones de dólares, unos 14 millones de euros al cambio de entonces, fue aprobada por Consejo de Ministros de 4 diciembre de 1987, a un tipo de interés de un 3 por 100, con un periodo de amortización de diez años, en el que se incluía una carencia de siete años.

\section{8}

Se concedió un crédito FAD para la construcción de una planta de detergentes por importe de 36,06 millones de euros, con unas condiciones financieras de quince años de amortización, diez de carencia y un tipo de interés del 1,5 por 100 .

\section{9}

Se aprobaron por Consejo de Ministros facilidades financieras para China con cargo al FAD por importe de 68,09 millones de euros, entre las que se incluían dos líneas de crédito para pequeños proyectos por un importe de 15 millones de dólares cada una, equivalente a unos $9,8 \mathrm{mi}-$ llones de euros, y se aprobaron seis proyectos, dos de ellos consistentes en el suministro de bienes de equipo para la construcción de una planta del sector textil y para la ampliación de una planta de cemento. Un proyecto consistió en la instalación de una central térmica en Ligang por 24,5 millones de euros y los tres proyectos restantes se enmarcaron dentro del sector de las telecomunicaciones con la instalación de líneas telefónicas en tres provincias chinas, Hubei, Wuhan y Zhejiang. Los tipos de interés de estos créditos se situaron en el 1,5 y el 2 por 100 y las amortizaciones oscilaron entre 30 y 20 años. Para las líneas de crédito los periodos de amortización no superan los 15 años.

\section{0}

Las facilidades financieras aprobadas alcanzaron un importe de 55,36 millones de euros, entre las que se incluyen una línea de crédito para pequeños proyectos de 30 millones de dólares, 18,39 millones de euros. Los cuatro créditos aprobados fueron del sector de las telecomunicaciones. Se suministraron e instalaron centrales telefónicas y líneas de teléfono en las provincias de Liaoning, Sichuan, Shanghai, Dtong y Taiyuan, a un tipo de interés de 1,50 por 100 , con 30 años de amortización y 10 de carencia. 


\section{1}

De las nueve operaciones aprobadas, tres fueron del sector de las telecomunicaciones, en centrales telefónicas en Yunnan, Zheijiang y Wuxi, y las seis restantes de bienes de equipo para plantas de polietileno, polipropileno, óxido etileno y planta de cemento. Todas con una amortización de 30 años y una carencia de 10, a un tipo de interés de 1,25 por 100. El año 1991 fue el periodo en que se aprobó la mayor cantidad de fondos con cargo al FAD para China, 135,57 millones de euros, incluyendo facilidades para tres líneas de crédito de pequeños proyectos, por importe equivalente a unos 10 millones de euros cada una.

\section{2}

Se aprobaron tres créditos en las mismas condiciones financieras del año anterior, la construcción de una acería en Wuhan por 93,11 millones de euros y sendas centrales telefónicas en la Mongolia Interior y en la provincia de Ganzu, por importe no superior a los 9 millones de euros cada operación. El total FAD aprobado fue de 109,17 millones de euros.

\section{3}

De un total de 62,97 millones de euros, 7,3 millones fueron a una línea de crédito para pequeños proyectos. Se aprobaron seis créditos, dos para el sector eléctrico, uno en el sector bienes de equipo de suministro de máquina herramienta en Meizhou, uno en el sector de transporte de sistema de control de tráfico en Changchun y dos en el sector medioambiental de aguas, con la construcción de una planta de agua potable en Zhangzhou y dos depuradoras en Xiamen. Los tipos de interés en este año fluctuaron entre el 2,50 por 100 con amortizaciones de 21 años y carencia de 10 , y el 0,20 y el 0,30 por 100 con 35 o 39 años de amortización y 12 o 13 de carencia.

\section{4}

El total de fondos FAD aprobado fue de 59,77 millones de euros, de los cuales unos $15,8 \mathrm{mi}-$ llones fueron para cada una de las dos líneas de pequeños proyectos aprobadas. Las dos operaciones imputadas a este ejercicio se encuadran dentro del sector de bienes de equipo, con 30 años de amortización, 10 de carencia y 0,20 de interés.

\section{5}

Tres grandes proyectos fueron financiados con créditos FAD, uno para la construcción de una planta de detergentes por 54,10 millones de euros, una planta de fundición de bloques de motor por 9,35 millones de euros y tres líneas de prensa de control numérico por 13,9 millones de euros. La financiación concedida fue a unos tipos de interés del 0,35 por 100 a 30 años con 10 de carencia. El total FAD aprobado fue de 115,68 millones de euros; unos 15 millones para cada una de las dos líneas de pequeños proyectos aprobadas. Fue, junto con 1991 y 1992, el año en que se destinaron mayores recursos financieros.

\section{6}

Solo se aprobó un crédito FAD por importe de 1,8 millones de euros para una planta de agua potable para la ciudad de Ruian, en la provincia de Zhejiang, a 30 años y 1,5 por 100 de tipo de interés

\section{7}

Los seis proyectos aprobados se encuentran dentro de los sectores de bienes de equipo, telecomunicaciones, transporte, electricidad eólica y medioambiente en aguas. Para los proyectos eólicos la amortización de los créditos se fijó en 19 años, con carencia de 5 a un interés del 1,5 por 100; para el resto de los créditos subieron de 30 años a 33, con un interés del 1,00 y 0,30 por 100 respectivamente. El importe FAD aprobado alcanzó los 64,77 millones de euros.

\section{8}

De un total FAD por importe de 32,11 millones de euros, se aprobaron seis créditos, entre ellos dos parques eólicos en Dongshan y Pingtan, generadores eólicos para Gansu, un sistema de control de tráfico para la autopista Nanjing-Shanghai y dos plantas de agua potable en Chenbei y $\triangleright$ 
Xining. Las condiciones financieras fueron para todos 30 años de amortización y 10 de carencia, a un tipo de interés del 1,00 y del 0,80 por 100 . A una línea de crédito de pequeños proyectos se dedicaron 16,89 millones de euros.

\section{9}

Se adjudicaron 77,25 millones de euros a China, de los cuales 19,71 fueron a una línea de pequeños proyectos. Se aprobaron 10 créditos FAD, entrando en el sector de la sanidad con el suministro de equipamiento médico para cuatro hospitales en las provincias de Xiamen, Haikou y Chongquing y para un hospital público. Cuatro créditos dentro del sector medioambiental, dos de aguas, consistentes en una planta de tratamiento de agua potable en Qinpu y una depuradora de aguas residuales en Taixing y dos plantas incineradoras de residuos sólidos urbanos en Shanghai y en Pekín. En el sector eléctrico se construyó un parque eólico en Xiling (Mongolia Interior) y se suministraron dieciséis aerogeneradores en Nan'ao, en la provincia de Guangdong. Las condiciones financieras siguieron siendo a unos 30 años y los tipos de interés a un 1 por 100 .

\section{0}

Con apoyo oficial a través de créditos FAD, a un tipo de interés del 0,80 por 100 , con 30 años de amortización y 10 de carencia, se suministró equipamiento médico para cuatro hospitales en Yunan Dali, Beiahi, Naning y Yangling, se financiaron dos proyectos de sistema de control de tráfico urbano en Zhengzhou y para la autopista Yantiang-Bangang, y se suministraron bienes de equipo para una fábrica de motores automovilísticos en Huandong. En total fueron nueve créditos por un importe total de 25,5 millones de euros.

\section{1}

Se financiaron, en las mismas condiciones del año anterior, nueve proyectos por importe FAD de 99,13 millones de euros, dos en el sector de la sanidad con equipamiento médico para los hospitales de Suquian y Yalan Wuhan, un centro de formación profesional de máquina herramienta, un sistema de riego para invernaderos en Xinjiang, una planta de refino de aceite vegetal en Anhui y una planta de clorometano en Sichuan; en el sector medioambiental se equipó una planta de tratamiento de residuos sólidos urbanos en Zunyi, un proyecto de acceso de billetes para la línea 3 del metro de Sanghai y un centro de entrenamiento de pilotos de líneas aéreas en Hainan.

\section{2}

Por importe de 27,00 millones de euros, a un tipo de interés que bajó en las últimas operaciones hasta un 0,20 por 100, se financiaron en total siete proyectos, dos en el sector de la sanidad, suministrando equipamiento médico a los hospitales de Shanghai East y Wuyang (Henan); en Xian, dos proyectos de infraestructuras de distribución y de almacenamiento de gas natural, un sistema de control de acceso a túneles de autopistas, una planta de aguas residuales en Hunan y dos plantas de tratamiento de fangos.

\section{3}

Con 92,74 millones FAD se financiaron veinte proyectos, ocho proyectos de equipamiento médico para tres hospitales en Sichuan, en Jiansu y en Xinjiang, dos en Henan y uno en Mongolia Interior, un proyecto de control de tráfico en Wuhan y un sistema de vigilancia y control de autopistas en Pekín. A su vez, se financiaron en Tianjin, para el tren ligero, el mantenimiento del tren, el de las ruedas y el de los raíles, por tres empresas distintas, un sistema de radiocomunicaciones, otro de control de acceso al tren y otro para el tendido aéreo de la catenaria. En bienes de equipo se financió el equipamiento agrícola para invernaderos en Shanghai y en Wuhan (Hubei), un desarrollo ganadero integral en Sishui, una planta de producción y refino de aceite vegetal en Lingzong y el suministro ganadero para una granja de producción de leche en Wusu (Xinjiang). En el sector medioambiental se construyó una planta de tratamiento de fangos en Tianjin. Los tipos de interés fueron, en general, del 0,20 por 100. Para una línea de crédito para pequeños proyectos se aprobaron 25,8 millones de euros. 


\section{4}

Se financiaron 24 proyectos, por un importe total de 44,24 millones de euros a tipos de interés entre el 0,20 y el 0,80 por 100 a plazos entre los 25 y 36 años de amortización. Junto con 2003, fueron los dos años en los que se formalizaron un mayor número de operaciones de exportación con apoyo oficial FAD. En el sector de sanidad se concedieron facilidades financieras para el suministro de equipamiento hospitalario para seis hospitales en distintas provincias chinas, una planta de producción y refino de aceite vegetal en Yiyang (Hunan), el suministro de máquina herramienta para la fabricación de material rodante ferroviario en Quindao (Shandong), el suministro e instalación de equipos para la fabricación de bloques y bordillos de cemento en Hubei, el suministro e instalación de dos plantas deshidratadoras de alfalfa en Shanhi, el suministro y equipamiento para la segunda fase de construcción de la red de distribución de gas en la ciudad de Luoyang y el suministro e instalación de cuatro invernaderos en Hebei. En el sector ferroviario, para la línea 1 del metro de Tianjin, se financió un sistema de control, acceso y cobro, un sistema de alimentación eléctrica, una máquina esmeriladora, el diseño, la fabricación y el montaje del torno para el foso de mantenimiento de las ruedas de los trenes y equipos para el lavado de los trenes. Asimismo, un sistema de control de tráfico urbano en Xinxiang, el suministro e instalación de un sistema de radiocomunicaciones también en Tianjin, el suministro e instalación de catorce turbinas eólicas en Yumen (Gansu), y equipos y transmisión de TV en Xiangxi. En el sector de la educación, un equipamiento para una escuela de profesores en Pingdingshan, y en el sector medioambiental, una planta de tratatamiento de fangos.

\section{5}

Por 99,66 millones FAD se financiaron dos equipamientos hospitalarios en Anhui $y$ en Chongqing, un suministro de equipamiento contra incendios y protección civil, un equipamiento digital para la programación y difusión de programas de televisión, el equipamiento de laboratorios de la Universidad de Jilin, el equipamiento para una planta de procesado de alfalfa en Gansu, un sistema de gestión de tres autopistas en Shanxi y la electrificación de la línea ferroviaria TianjinShenyang. Los intereses no subieron del 0,20 por 100 y los plazos de amortización entre los 31 y 36 años. 50 millones de euros se adjudicaron a una línea de crédito.

\section{6}

Se financiaron con 43,92 millones de euros FAD dos proyectos de suministro e instalación de equipos médicos en Shandon y Gansu, el suministro e instalación de un equipo educativo en Guanxi, el suministro e instalación de dieciséis turbinas eólicas para el parque eólico de Jigong, la ampliación de la red de gas natural de la ciudad de Lanzhou, un proyecto integral de seguridad y el control de tráfico en Erdos en la Mongolia Interior. Los tipos de interés oscilaron entre el 0,15 y el 0,20 por 100 .

\section{7}

Se financió un proyecto de seguridad y control de tráfico en Jincheng (Shanxi) y el nuevo recinto ferial internacional de Pekín. El importe FAD ascendió a 13,8 millones de euros y los tipos de interés, entre el 0,15 y el 0,10 por 100 .

\section{8}

Se aprobaron dos líneas de crédito, cada una por 20 millones de euros. Una para reparar los daños de las áreas afectadas por un terremoto, de la que no se llegó a efectuar ninguna disposición, y la otra fue una línea de pequeños proyectos.

\section{9}

Con 77,73 millones de euros FAD se aprobó una línea de crédito para pequeños proyectos por importe de 40 millones y una operación de equipamiento del sistema de electrificación del ferrocarril Xinxiang-Heze-Yanz-Hou-Rizhao. Fue el último año de utilización del FAD en China. 